\title{
Phylogenic points of view on the sexuality of cormophytes
}

\author{
MICHEL FAVRE-DUCHARTRE
}

Laboratoire de Botanique, Faculté des Sciences de Reims, B. P. 347, 51062 Reims-Cedex, France

\begin{abstract}
1) Unisexuality is spreading from gametes, through gametophytes, to sporangia and sporophytes, individual hermaphrodite plants finally becoming the ground for sex separation with cross fertilization processes; 2) male and female gametogeneses are obbreviated down to the production of 3 - and 4 cell gametophytes respectively; 3) inter-archegonial double fertilizations are found elsewhere than in angiosperms; 4) in the embryo sacs of the latter the disparity of female structures linked with disynchronic post-fertilization developments might explain the differences between the endosperm and the embryo.
\end{abstract}

As an overall introduction let us point out that gametes, gametophytes, sporangia and sporophytes are progressively acquiring an exclusive male or female character (Fig. 1). (F a vre-Duchartre, 1970). However, cross-fertilization processes appear in angiosperms as a separation of sexes within one and the same sporophyte.

Spermatocytes (Fig. 2), which are naked in Chlorophyceae, become protected in antheridia in all cormophytes. In bryophytes and pteridophytes, several antheridial peripheric sterile cells and spermatocytes constitute the male gametangium; whereas in ovulated plants, a unique sterile cover cell, the so-called "tube-cell", protects but two male gametes. The neoteinic reduction of male gametophytes might, theoretically, be more accentuated if it were limited to an antheridium containing a unique gamete or even to a one-cell pollen tube, then playing the role of a naked spermatocyte.

Along with different angiosperm taxa, exine presents an archaic thick homogeneous or more and more advanced structures (alveolate, baculate, atectate or total absence): this implies that the angiosperm ancestors are to be looked for deeper than among the present heterosporous pteridophytes the exine of which is of alveolate type.

In cormophytes, oocytes (Fig. 3) are incorporated into the archegonia which become fertile earlier and earlier in development (down to the archegonium-initial stage) as the cormophyte taxa are more advanced. 


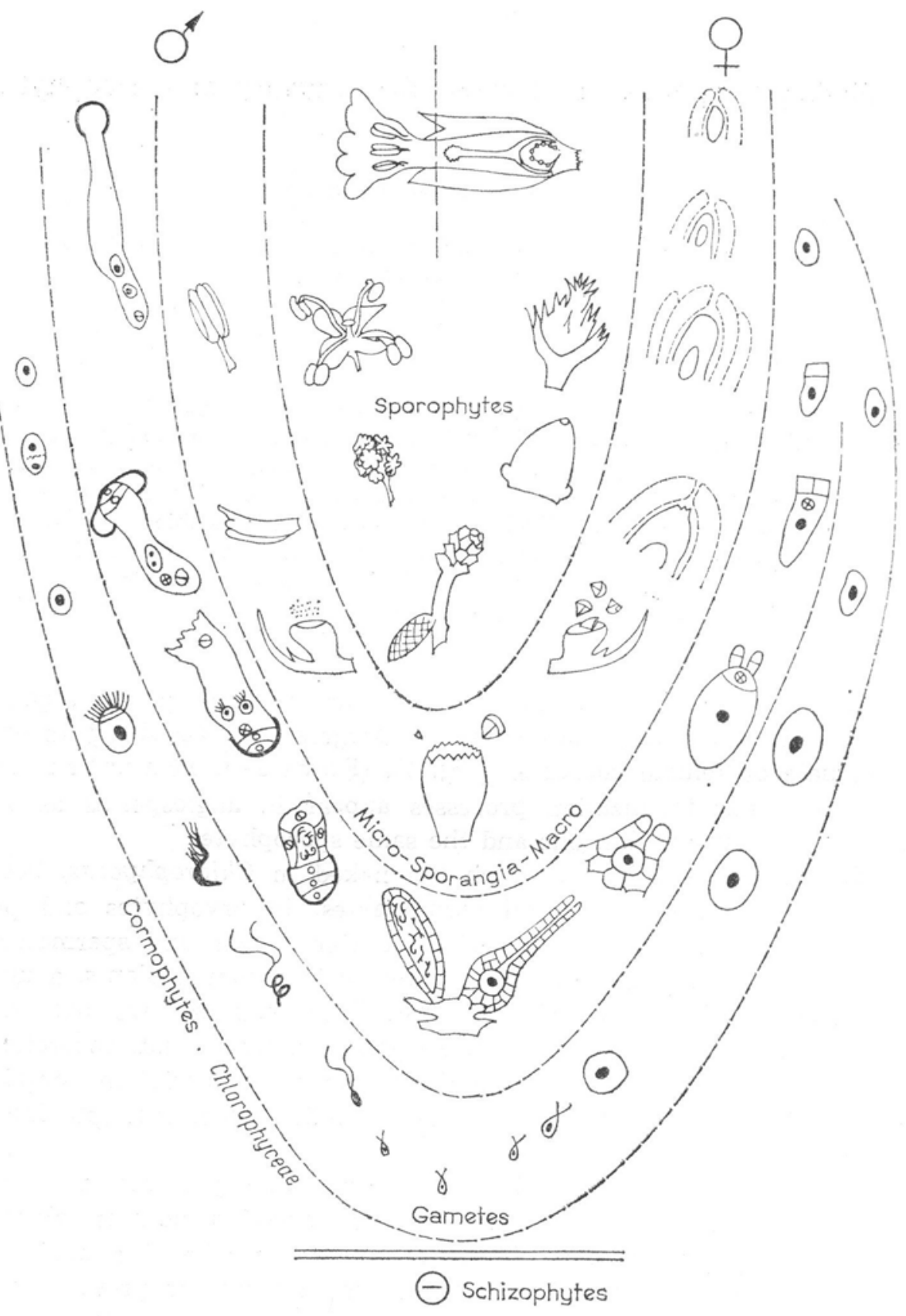

Fig. 1. A proposal for plant sexuality overall phylogenesis 


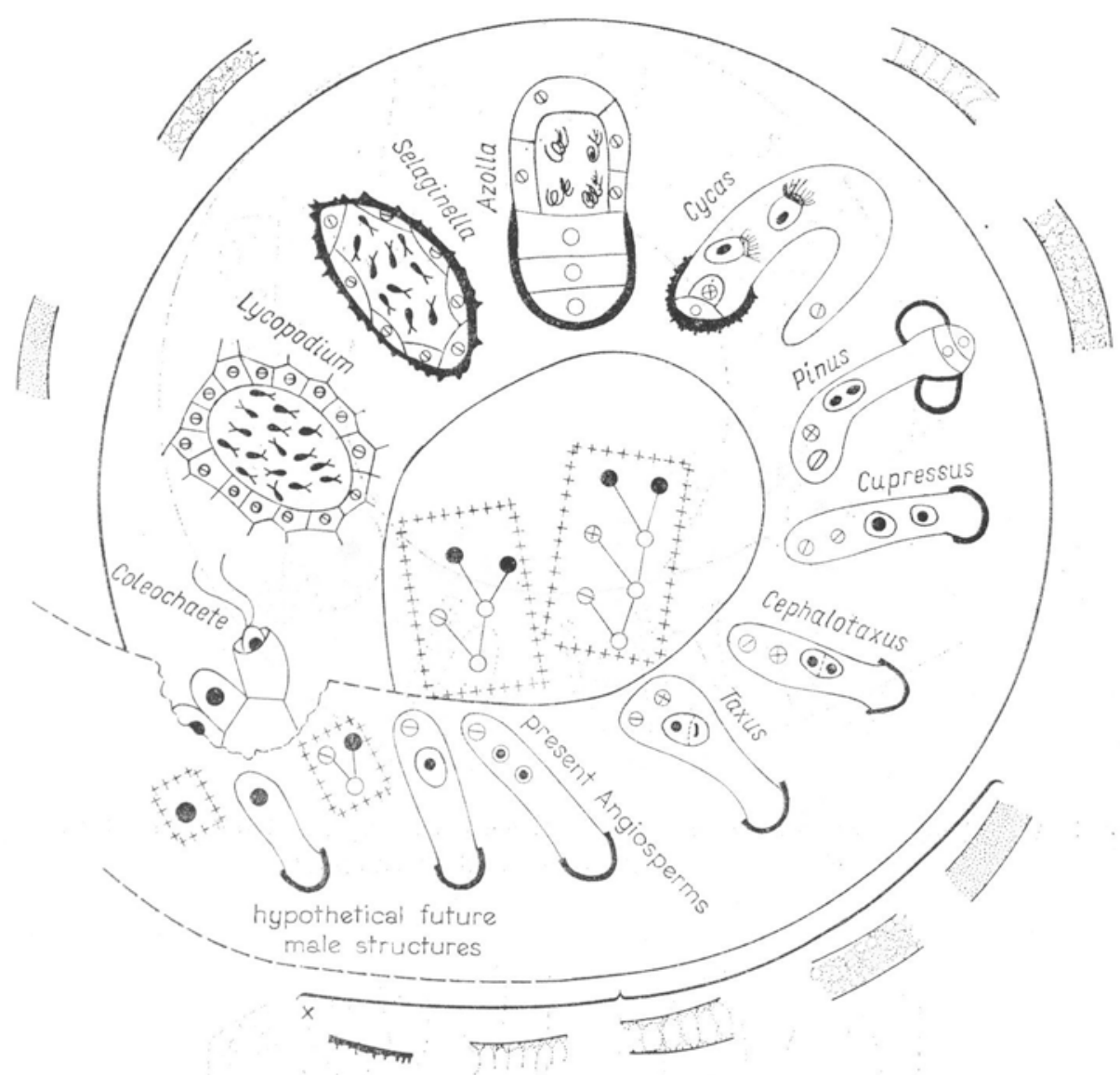

Fig. 2. Suggested evolutionary trend from naked Chlorophyceaé spermatccytes through more and more reduced antheridia returning (in a hypothetical future) to a naked male gametocyte

In the four insertions, from right to left, more and more abbreviated spermatogeneses are presented; outside the helicoid path some exine siructures regarding the considered taxa are figured.

A maturation desynchronisation through the different archegonial structures of one and the same gametophyte is obvious in evolved gymnosperm genera (Fig. 4). Among the 8 free embryo sac nuclei of Nicotiana, those of future 1) synergids, 2) marginal egg and 3) central cell are recognizable because of their relative positions, sizes and stainabilities (B a nnikova, 1971). I interpret those differences as manifestations of successive female structure maturations occuring also in angiosperms; the main originality, here, would consist in the fact that, owing to the dastic female gametogenesis abbreviation, the delayed differentiation of the marginal egg cell (Fig. 3, 4) would be precociously interrupted and fixed in the state of a fertilizable archegonium-initial. 


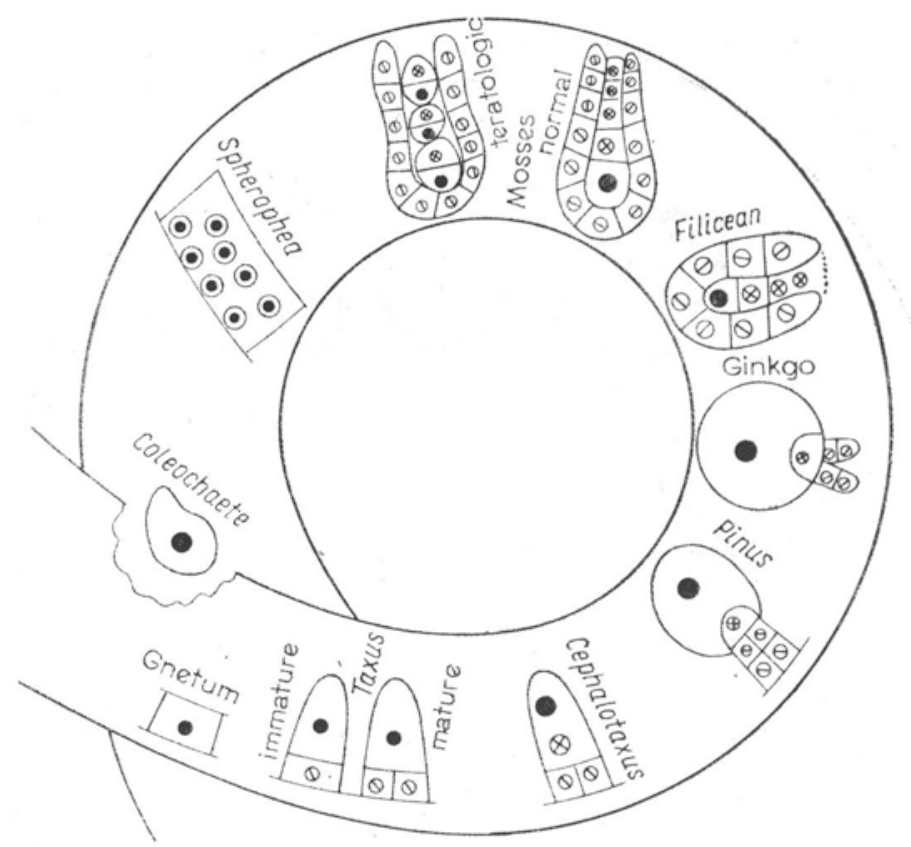

Fig. 3. Visualization of female sexual structures occurring at different evolutionary levels of Chlorophyceae and cormophytes
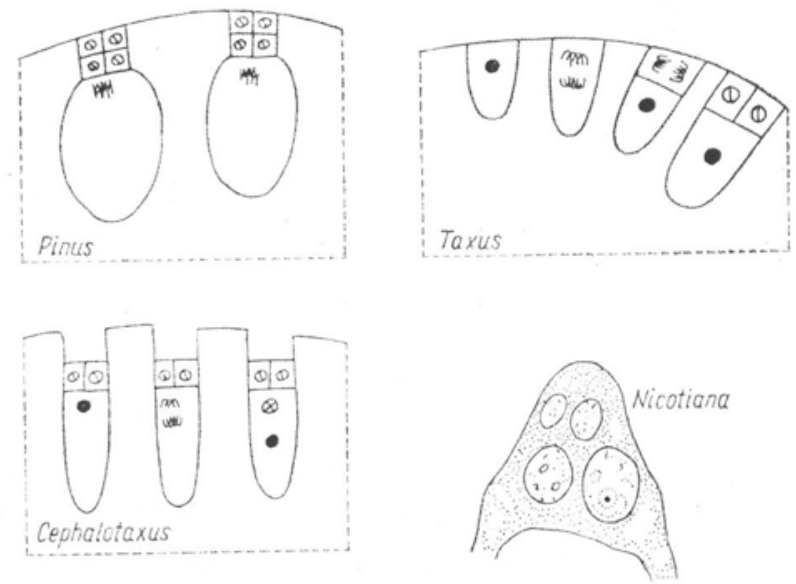

Fig. 4. Oogeneses primitively synchronous (Pinus) are becoming desynchronized in Cephalotaxus, Taxus and angiosperms

Double fertilizations (Fig. 5) are of common occurrence in non-angiospermic cormophytes and are even generalized in some gymnosperm taxa (C h e s n o y, 1977).

In most angiosperms, the primary endosperm nucleus undergoes mitosis as soon as the central caryogamy is over, giving rise to the endo- 


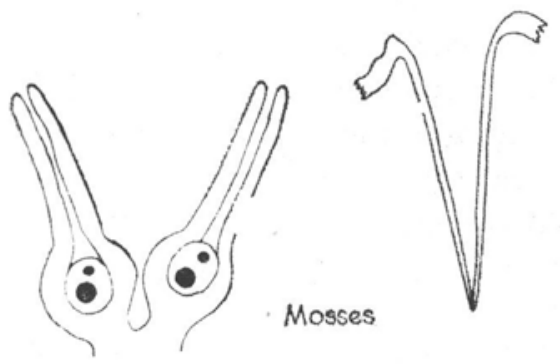

\section{Cupressaceae}
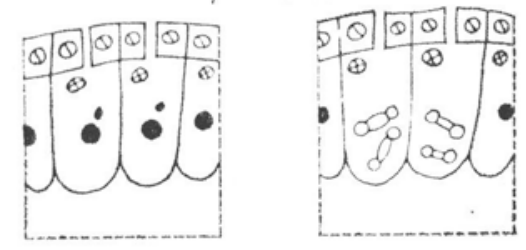

Fig. 5. Occurrence of inter-archegonial double fertilizations and their results, extrinsically to angiosperms

sperm (Fig. 6) ... as is the case for gymnosperms' zygotes which produce a proembryo under the cover of neck-cells, whereas the marginal zygotes of Gnetum and angiosperms stagnate several days before forming an early differentiated true embryo.

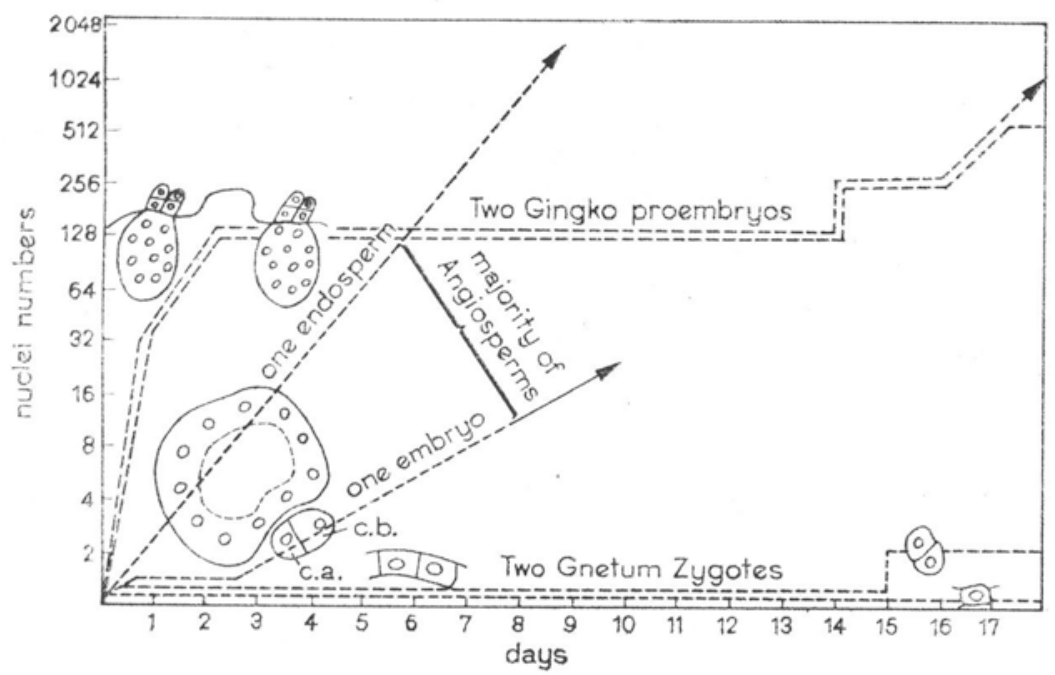

Fig. 6. Comparison between: 1) undelayed and rapid development of central zygotes giving rise to gymnosperm proembryos or angiospermous endo-sperms; 2) marginal zygote stagnation succeeded by angiosperm and Gnetum embryogeneses 
Compared to the gymnosperm proembryos, the angiospermous endosperms have the peculiarity never to differentiate organs, probably in connection with their rapid and uninterrupted development. However, the sexual origin of angiospermous endosperms as well as their occasionall manifestation of paternal characters indicate a sharp difference between those polyploid organisms and the female haploid gymnospermic ones. An analogy betwen gymnosperm endosperms and those of angiosperms is the fact of a convergence; but the fundamental lack of homology justifies the Polish term "bielmo", the Slovakian "bielok", as well as the Roumanian and French "albumen" to distinguish the nutritive angiospermous organism from the gymnospermous one, to which the term "endosperm" might be restricted.

\section{REFERENCES}

Bannikova V. P., 1971. Development features of female gametophyte of $\mathrm{Ni}$ cotiana. Ann. Univ. et A. R. E. R. S., Reims 9: 73-77.

Chesnoy L., 1977. Etude cytologique des gamètes, de la fécondation et de la proembryogenese chez le Biota orientalis Endl. III. Fécondation et proembryogenèse; transmission du cytoplasme du gamète mâle au proembryon. Rev. Cytol. Biol. Vég. 40: 293-396.

Favre-Duchartre M., 1970. Des ovules aux graines. Paris, 136 p. 